\title{
PENGARUH WORK LIFE BALANCE TERHADAP KINERJA KARYAWAN PADA KARYAWAN STAFF PRODUKSI PT. MUARA TUNGGAL CIBADAK - SUKABUMI
}

\author{
Ranti Lukmiati ${ }^{1}$, Acep Samsudin ${ }^{2}$, Dicky Jhoansyah ${ }^{3}$ \\ Fakultas Ilmu Administrasi dan Humaniora, Program Studi Administrasi Bisnis \\ Universitas Muhammadiyah Sukabumi \\ $\underline{\text { rantilukmiati002@ummi.ac.id }}^{1}$, acepsamsudin@ummi.ac.id $^{2}$,dicky.jhoansyah@ummi.ac.id $^{3}$
}

\begin{abstract}
ABSTRAK
Penelitian ini bertujuan untuk mengetahui seberapa besar pengaruh Work Life Balance dalam meningkatkan kinerja karyawan staff produksi PT.Muara Tunggal, metode yang digunakan dalam penelitian ini adalah metode penelitian kuantitatif dengan analisis regresi linier sederhana sebagai teknik analisa data, dengan jumlah responden sejumlah 46 orang yaitu dengan menggunakan survey melalui kuesioner kepada 46 karyawan PT. Muara Tunggal, hasil penelitian ini dapat menunjukan bahwa Work Life Balance berpenguh positif dan signifikan terhadap kinerja karyawan. Total pengaruhnya sebesar $61,6 \%$, sisanya sebesar $38,4 \%$ dipengaruhi oleh variabel yang tidak diteliti dalam penelitian ini .
\end{abstract}

Kata kunci: Work Life Balance, Kinerja Karyawan

\section{ABSTRACT}

This study aims to determine how much influence the Work Life Balance has on improving the performance of PT. Muara Tunggal production staff, the method used in this study is a quantitative research method with simple linear regression analysis as a data analysis technique, with 46 respondents consisting of 46 using a survey through a questionnaire to 46 employees of PT. Muara Tunggal, the results of this study can show that Work Life Balance has a positive and significant impact on employee performance. The total effect is $61.6 \%$, the remaining $38.4 \%$ is influenced by variables not examined in this study.

Keywords: Work Life Balance, Employee Performance

\section{PENDAHULUAN}

Di era globalisasi ini persaingan dalam dunia bisnis semakin ketat, Salah satu industri yang saat ini memiliki persaingan yang semakin ketat yaitu industri garment atau tekstil. Di kabupaten Sukabumi sendiri telah berdiri beberapa industri garment. Tentu dengan maraknya industri yang serupa seperti ini perusahaan harus mampu berinovasi agar dapat mempertahankan usaha mereka, dalam hal ini perusahaan berlomba - lomba mendapatkan keuntungan yang maksimal dengan sumber daya yang minimal.

Diantara sumber daya yang paling berpengaruh, sumber daya manusia merupakan salah satu sumber daya yang paling menentukan kelanjutan perusahaan tersebut, maka dari itu para pimpinan perusahaan dituntut pula untuk bagaimana memelihara sumber daya manusia yang baik.

Salah satu masalah yang sering muncul mengenai Sumber Daya Manusia adalah menurunnya kinerja karyawan yang bisa disebabkan oleh beberapa faktor, baik itu faktor dari dalam lingkungan perusahaan sendiri, maupun faktor dari luar perusahaan, dengan menurunnya kinerja karyawan tentu juga mengakibtakan menurun pula hasil serta kualitas produk yang dihasilkan, yang tentunya dapat menjadikan perusahaan tidak mampu bersaing dengan industri yang serupa yang ada di wilayah tersebut.

Penurunan kinerja karyawan salah satunya disebabkan oleh tidakadanya keseimbangan antara kehidupan pribadi dan pekerjaan atau Work Life Balance. Salah satu upaya menjaga dan mempertahankan kinerja karyawan yang baik adalah dengan system Work Life Balance. Hal ini sesuai dengan survey Robert Walters, Lembaga Rekrutmen Profesional Global mengungkapkan ada tiga hal yang diminta pekerja kepada perusahaan agar dapat bekerja 
dengan baik, salah satunya adalah Work Life Balance. Hal ini harus disadari oleh perushaan karena karyawan bukan hanya memilki tanggung jawab pekerjaan namun juga tanggung jawab pribadi diluar pekerjaan seperti keluarga, jadi sebisa mungkin karyawan dapat menyeimbangkan waktu bekerja dan waktu pribadi diluar pekerjaan.

Salah satu perusahaan garmen di kabupaten Sukabumi yaitu PT. Muara Tunggal mulai menyadari pentingnya Work Life Balance dalam kehidupan karyawan, hal ini bukan tanpa alasan, karena dalam praktek nya seringkali karyawan tidak fokus dalam pekerjaan nya, bahkan beberapa mengeluhkan bahwa mereka tidak mampu membagi waktu antara kehidupan pribadi atau keluarga dan urusan pekerjaan, sehingga sering terjadi karyawan lebih mementingkan urusan pekerjaan dibanding urusan pribadi ataupun sebaliknya, dalam hal ini mereka tidak mampu memilih mana yang harus di prioritaskan. Akibatnya banyak diantara mereka yang mengalami penurunan kinerja

Akibat dari penurunan kinerja ini salah satunya adalah meningkatnya absensi ketidakhadiran karyawan. Dari latar belakang diatas peneliti akan mengukur sejauh mana peran Work Life Balance dapat mempengaruhi kinerja pergawai staff produksi di perusahaan garment PT. Muara Tunggal dan mengangkat judul "Pengaruh Work Life Balance terhadap Kinerja Karyawan (Survey staff produksi PT. Muara Tunggal)".

\section{TINJAUAN TEORI DAN PENGEMBANGAN HIPOTESIS Work Life Balance}

Work Life Balance adalah sejauh mana keterlibatan dan kepuasan individu dalam peran mereka diantara kehidupan pribadi dan kehidupan pekerjaan serta tidak menimbulkan konflik diantara keduanya (Ula, Susilawati, \& Widyasari, 2019). Sedangkan menurut Delecta (dalam Hafid, 2017), Work Life Balance adalah kemampuan individu untuk menjaga keseimbangan antara kewajiban mereka di tempat kerja dengan kebutuhan pribadi diluar pekerjaan.

Berikut ini dimensi Work Life Balance menurut Fisher, Bulger dan Smith (dalam Ula et al., 2019): 1) Work Interference with Personal Life (WIPL) dimensi ini mengacu pada seberapa jauh pekerjaan mengganggu urusan pribadi, 2) Personal Life Interference with Work (PLIW) dimensi ini mengacu pada seberapa jauh kehidupan pribadi mengganggu ururusan pekerjaan, 3) Personal Life Enhancenment with Work (PLEW) dimensi ini mengacu pada seberapa jauh kehidupan pribadi dapat meningkatkan kualitas kinerja individu di tempat kerja, 4) Work Enhancenment with Personal Life (WEPL) dimensi ini mengacu pada seberapa jauh urusan pekerjaan dapat meningkatan kualitas kehidupan pribadi individu.

\section{Kinerja Karyawan}

Menurut Mangkunegara (dalam Saina, Pio, \& Rumawas, 2016), Kinerja berasal dari kata Job Performance atau Actual Performance atau bisa diartikan sebagai kualitas dan kuantitas hasil kerja seseorang sesuai dengan tanggung jawab yang diberikan kepadanya. Sedangkan Jex dan Brit (dalam Sarikit, 2017) mengemukakan bahwa kinerja adalah keseluruhan perilaku pegawai dalam bekerja yang tidak hanya berhubungan dengan kinerja tugas, akan tetapi juga berhubungan dengan tanggung jawab karyawan terhadap tugasnya.

Berikut ini adalah dimensi Kinerja Karyawan menurut Bernadin dan Russel (dalam Setiawan, 2015), 1) Kualitas, yaitu seberapa baik produk yang dihasilkan dan sesuai yang diharapkan, 2) Kuantitas, yaitu seberapa banyak produksi yang dihasilkan, apakah sudah mencapai target atau tidak. 3) Ketepatan waktu, yaitu berapa lama waktu yang dibutuhkan dalam mencapai target produksi apakas sudah sesuai atau belum. 4) Efektifitas Biaya, yaitu bagaimana perusahaan dapat memanfaatkan segala sumber daya yang ada untuk memperoleh keuntungan dan menghindari kerugian. 5) Hubungan antar perseorangan, yaitu seberapa baik hubungan yang terjalin antar sesame individu atai karyawan di tempat kerja sehingga terjadi komunikasi dan kerja sama yang baik antar sesame karyawan. 


\section{PENGEMBANGAN HIPOTESIS}

Penelitian ini dilakukan untuk mengetahui seberapa besar pengaruh Work Life Balance sebagai variable $\mathrm{x}$ terhadap Kinerja Karyawan sebagai variable y. penelitian yang sama pernah dilakukan oleh (Dina, 2018), dengan judul Pengaruh Work Life Balance terhadap Kinerja Karyawan di KUD Minatani Brondong Lamongan dengan hasil penelitian yaitu Work Life Balance berpengaruh sebesar $65,1 \%$ terhadap kinerja karyawan dan sisanya dipengaruhi oleh variable lain yang tidak di teliti dalam penelitian tersebut.

\section{METODE PENELITIAN}

Penelitian ini dilakukan di PT. Muara Tunggal Kabupaten Sukabumi, dengan pendekatan Sumber Daya Manusia. Dalam penelitian ini terapat dua variable yaitu variable Work Life Balance (X1) sebagai variable bebas atau independent dan variable Kinerja Karyawan (Y) sebagai variable terikat atau dependent.

Penelitian ini terdiri dari variable Work Life Balance dan Kinerja Karyawan. Adapun dimensi dari variable Work Life Balance sebagai variable bebas diantaranya: 1) Work Interference with Personal Life, 2) Personal Life Interference with Work, 3) Work Enhancement with Personal Life, 4) Personal Life Enhancement with Work. Sedangan dimensi dari variable Kinerja Karyawan sebagai variable terikat diantaranya: 1) Kualitas, 2) Kuantitas, 3) Ketepatan Waktu, 4) Efektifitas Biaya, 5) Hubungan antar perserorangan.

Sampel dalam penelitian ini adalah staff produksi PT. Muara Tunggal yang berjumlah 46 orang, metode yang digunakan dalam pengambilan sampel adalah teknik probability sampling dengan sample jenuh.

\section{HASIL DAN PEMBAHASAN}

Adapun hasil yang diperoleh peneliti setelah melakukan penyebaran kuesioner melalui google from yaitu sebagai berikut:

Tabel 1. Hasil Uji Validitas X dan Y

\begin{tabular}{ccccc}
\hline Variabel & Rhitung & Rtabel & Sig. & Hasil \\
\hline X1 & 0,615 & 0,255 & 0.000 & Valid \\
X2 & 0,750 & 0,255 & 0.000 & Valid \\
X3 & 0,577 & 0,255 & 0.000 & Valid \\
X4 & 0,622 & 0,255 & 0.000 & Valid \\
X5 & 0,688 & 0.255 & 0.000 & Valid \\
X6 & 0,745 & 0.255 & 0.000 & Valid \\
X7 & 0,641 & 0.255 & 0.000 & Valid \\
X8 & 0,581 & 0.255 & 0.000 & Valid \\
Y1 & 0,660 & 0,255 & 0.000 & Valid \\
Y2 & 0,555 & 0,255 & 0.000 & Valid \\
Y3 & 0,664 & 0,255 & 0.000 & Valid \\
Y4 & 0,773 & 0,255 & 0.000 & Valid \\
Y5 & 0,749 & 0,255 & 0.000 & Valid \\
Y6 & 0,669 & 0,255 & 0.000 & Valid \\
Y7 & 0,410 & 0,255 & 0.000 & Valid \\
Y8 & 0,704 & 0,255 & 0.000 & Valid \\
\hline
\end{tabular}

Sumber : Diolah peneliti, 2020

Tabel 2. Hasil Uji Reliabilitas Y Dan X

\begin{tabular}{llll}
\hline Reliability Statistic Y & Reliability Statistic X \\
\hline Cronbach's Alpha & N of items & Cronbach's Alpha & N of item \\
0,805 & 8 & 0,804 & 8 \\
\hline
\end{tabular}

Sumber : Diolah peneliti,2020 
Reliabilitas variabel $\mathrm{Y}$ adalah 0,805 dan reliabilitas variabel $\mathrm{X}$ adalah 0,804 skor diatas $\mathrm{r}$ Kritis 0,2 maka akan dikatakan reliabel sehingga dapat mengukur analisis data.

Tabel 3. Analisis Regresi Linear

\begin{tabular}{|c|c|c|c|c|c|c|}
\hline \multicolumn{7}{|c|}{ Coefficients $^{\mathrm{a}}$} \\
\hline \multirow[b]{2}{*}{ Model } & & Unstandardize & Coefficients & $\begin{array}{l}\text { Standardized } \\
\text { Coefficients }\end{array}$ & & \\
\hline & & B & Std. Error & Beta & $\mathrm{T}$ & Sig. \\
\hline \multirow[t]{2}{*}{1} & (Constant) & 6,347 & 3,366 & & 1,886 & ,066 \\
\hline & $\mathrm{X}$ & 809 &, 096 &, 785 & 8,394 & 000 \\
\hline
\end{tabular}

Tabel diatas menjelaskan bahwa nilai konstansta sebesar 6,347 sedangkan nilai variabel X (Work Life Balance) 0,809 sehingga persamaan ditulis sebagai berikut :

$\mathrm{Y}=\mathrm{a}+\mathrm{bX}+\mathrm{e}$

$\mathrm{Y}=6,347+0,809+\varepsilon$

1. Persamaan diatas menjelaskan konstanta sebesar 6,347 yang berarti nilai konsisten variabel Y sebesar 6,347.

2. Koefisien regresi $\mathrm{X}$ sebesar 0,809 menyatakan bahwa setiap penambahan $1 \%$ nilai $\mathrm{x}$. maka nilai partisipasi bertambah 0,809 . Koefisien regresi bernilai positif dikatakan bahwa Work Life Balance terhadap kinerja karyawan adalah berpengaruh positif.

Tabel 4. Koefisien Korelasi

\begin{tabular}{lccccc}
\hline \multicolumn{5}{c}{ Model Summary } \\
\hline Model & $\mathrm{R}$ & R Square & $\begin{array}{c}\text { Adjusted R } \\
\text { Square }\end{array}$ & $\begin{array}{c}\text { Std. Error of the } \\
\text { Estimate }\end{array}$ \\
\hline 1 &, $785^{\mathrm{a}}$ &, 616 & &, 607 & 2,48237 \\
\hline a. Predictors: (Constant), X & & \\
\hline
\end{tabular}

Sumber : Diolah peneliti, 2019

Berdasarkan tabel diatas dijelaskan bahwa besarnya nilai korelasi ( $\mathrm{R}$ ) yaitu sebesar 0,785 dan diperoleh koefisien determinasi ( $\mathrm{R}$ Square ) sebesar 0,616 yang berarti bahwa variabel Work Life Balance ( $\mathrm{x}$ ) terhadap Kinerja Karyawan ( y) adalah sebesar 61,6 \%

Tabel 5. Hasil Uji F

\begin{tabular}{llrrrrr}
\hline \multicolumn{7}{c}{ ANOVA $^{\text {a }}$} \\
\hline Model & & Sum of Squares & df & Mean Square & F & Sig. \\
\hline 1 & Regression & 434,169 & 1 & 434,169 & 70,457 &, $000^{\text {b }}$ \\
& Residual & 271,135 & 44 & 6,162 & & \\
& Total & 705,304 & 45 & & & \\
\hline
\end{tabular}

a. Dependent Variable: Y

b. Predictors: (Constant), $\mathrm{X}$

Sumber : Diolah peneliti, 2020

Tabel ditas menjelaskan bahwa nilai Fhitung $=70,457$ dan nilai regresi memiliki tingkat signifikan $0.000<0.05$. maka dapat disimpulkan bahwa adanya pengaruh yang positif dan signifikan antara variabel Work Life Balance (x) terhadap variabel Kinerja Karyawan (y) . 


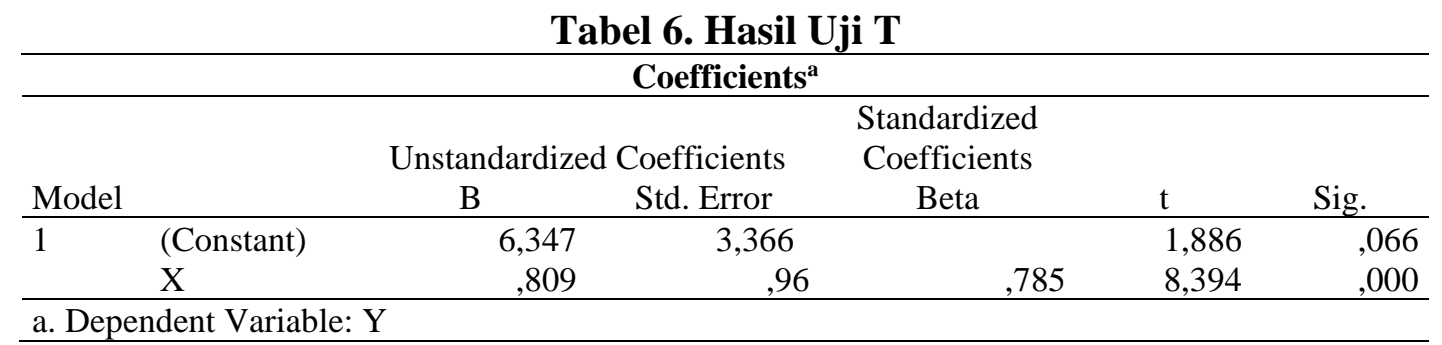

Sumber : Diolah peneliti, 2019

Tabel diatas menjelaskan bahwa nilai signifikan sebesar $0.000<0.05$. maka dapat disimpulkan adanya pengaruh positif dan signifikan antara Work Life Balance (x) dengan Kinerja Karyawan (y) . sedangkan nilai Thitung dan Ttabel yaitu 8,394 <. 2,051830516, maka dapat diartikan adanya pengaruh positif dan tidak signifikan antara Work Life Balance terhadap kinerja karyawan .

\section{PENUTUP}

\section{Kesimpulan}

Berdasarkan analisis yang dilakukan peneliti menemukan beberapa kesimpulan untuk menjawab pertanyaan pada penelitian ini . Dengan teknik analisis regresi sederhana diketahui bahwa total pengaruh variabel $\mathrm{X}$ terhadap variabel $\mathrm{Y}$ adalah sebesar 0,616 atau 61,6\% dan epsilon atau sisa pengaruh independent lainnya yang berpengaruh terhadap kinerja karyawan (Y) namun tidak diteliti adalah sebesar 0,384 atau 38,4\%.

Selanjutnya setelah dilakukan hipotesis secara parsial dan simultan didapatkan hasil penelitian yang menunjukan bahwa terdapat pengaruh yang positif dan signifikan antara variabel $\mathrm{X}$ terhadap Y,

\section{Saran}

Dalam penelitian yang akan datang,disarankan untuk menggunakan subvariabel lain agar dapat dijadikan sebagai alat ukur variabel kinerja karyawan dan memilih data lain sebagai referensi penelitian agar hasil penelitian lebih maksimal .

\section{DAFTAR PUSTAKA}

Dina, D. (2018). Pengaruh Work-Life Balance Terhadap Kinerja Karyawan di KUD Minatani Brondong Lamongan. Jurnal Indonesia Membangun, 17(2), 184-199. https://doi.org/10.1017/CBO9781107415324.004

Hafid, M. (2017). Pegaruh Work Life Balance terhadap Turnover Intention ( Studi Pada Karyawan Divisi Food \& Beverage Hotel Indonesia Kempinski Jakarta). XIV(3), 52-61.

Saina, I., Pio, R., \& Rumawas, W. (2016). Pengaruh Worklife Balance Dan Kompensasi Terhadap Kinerja Karyawan Pada Pt Pln (Persero) Wilayah Suluttenggo Area Manado. Jurnal Administrasi Bisnis UNSRAT, 4(3), 1-9.

Sarikit, M. (2017). Pengaruh Work Life Balance Dan Keterikatan Pegawai Terhadap Kinerja Pegawai Fakultas Ilmu Sosial Dan Ilmu Politik Universitas Indonesia. Jurnal Manajemen Pendidikan, 8(1), 82. https://doi.org/10.21009/jmp.08108

Setiawan, S. C. (2015). Pengaruh Motivasi Kerja Terhadap Kinerja Karyawan Level Pelaksana Di Divisi Operasi Pt. Pusri Palembang. Psikis: Jurnal Psikologi Islami, 1(2), 43-53.

Ula, I. I., Susilawati, I. R., \& Widyasari, S. D. (2019). Hubungan antara Career Capital dan Work-Life Balance pada Karyawan di PT. Petrokimia Gresik. Psikoislamika: Jurnal Psikologi Dan Psikologi Islam, 12(1), 13. https://doi.org/10.18860/psi.v12i1.6391 